\title{
Learned helplessness and response difficulty
}

\author{
PETER W. MORAN and MARION LEWIS-SMITH \\ State University of New York at Plattsburgh, Plattsburgh, New York 12901
}

\begin{abstract}
To determine the effects of preshock (PS) and sex on subsequent escape learning, 32 male and 32 female rats, approximately 90-110 days old were tested on barpress escape responding. The rats were randomly assigned to an inescapable PS treatment or the no-shock control treatment (C). These groups were further randomly assigned to four groups of four according to a required frequency of the barpress escape response, FR 2, FR 3, FR 4, and FR 5 . The results showed marked learning deficits in the PS groups at intermediate task-difficulty levels (FR 3 and FR 4). Female $C$ rats tended to have slightly lower mean escape latencies than male controls. There were no sex differences among the PS rats. Thus, helplessness was demonstrated at intermediate task levels (FR 3 and FR 4), but not at extreme levels (FR 2 and FR 5). An interesting interaction with sex was observed.
\end{abstract}

Rats exposed to a series of inescapable shocks show learning deficits when tested in a task requiring a novel escape response (e.g., Maier \& Testa, 1975; Seligman, Rosellini, \& Kozak, 1975). Seligman (1975) has labeled this finding "learned helplessness." Seligman theorizes that learned helplessness develops when there is an expectation that an outcome is independent of responding. Furthermore, having learned that an outcome is independent of responding interferes with learning, in other contexts, that a particular response will produce a consistent outcome. Rosellini and Seligman (1976) reported that rats exposed to inescapable shock subsequently failed to learn a barpress escape response, presumably because of prior learning that shock and responding were independent.

Previous learned helplessness research has examined numerous escape responses differing in both type and difficulty. Looney and Cohen (1972) were among the first to report the effects of inescapable shock using a jump-up escape response. They found that most inescapably shocked rats failed to escape on most test trials; those that did escape tended not to persist, but instead reverted to nonescape responses. Also using the jump-up response, Seligman and Beagley (1975) treated three groups of rats: escapably shocked, inescapably shocked, and control. In the treatment procedure, escapably shocked rats could terminate shock by barpressing. All rats in the escapably shocked group subsequently escaped shock during jump-up testing. Although the inescapably shocked rats showed substantial interference with jump-up escaping, it must be noted that the control rats also performed poorly in this task. These findings suggested that Looney and Cohen's jump-up escape response was not an appropriately sensitive index of the effects of inescapable shock on later escape responding.

Maier, Albin, and Testa (1973) studied the effects of inescapable shock on shuttlebox crossing, varying the difficulty of the escape response. There were three groups of treated rats: restrained, restrained and inescapably shocked, and control. All three groups were then tested in an escape task requiring a single crossing of a shuttlebox (FR 1). No escape latency differences were found between groups. The same three treatments were used in a subsequent experiment; however, the difficulty of the shuttlebox escape response was increased to two crossings (FR 2). Results revealed that the inescapably shocked group was slower to escape than the other two groups, which did not differ from each other. These findings suggested that inescapable shock tended not to interfere with a simple reflexive response (FR 1 shuttlebox crossing) but did interfere with a more difficult response (FR 2 shuttlebox crossings).

In another experiment, Seligman and Beagley (1975) examined response difficulty using barpress escape tasks. They tested rats treated with inescapable shock using FR 1, FR 2, and FR 3 barpresses. Compared with nonshocked controls, results showed that inescapable shock produced escape responding deficits only for the FR 3 task. Results for both shocked and control groups at each FR level showed that escape latencies increased as the difficulty of the escape response increased. These findings also suggest that the FR 3 barpress escape response is a sensitive index of the effects of treatment with inescapable shock.

Most studies demonstrating learned helplessness in rats have involved escape responses of FR 1, FR 2, and FR 3 difficulties. The present study examines the manipulation of barpress escape difficulties ranging from FR 2 to FR 5.

Studies of learned helplessness in rats generally use only male subjects. Research suggests that female rats are more active than males in stressful situations (e.g., Beatty \& Beatty, 1970; Davis, Porter, Burton, \& Levine, 1976; Denti \& Epstein, 1972; Hughes \& Bardo, Note 1). The present experiment examined effects of inescapable shock in both male and female rats. 


\section{METHOD}

Subjects

The subjects were 32 male and 32 female albino rats of the Sprague-Dawley strain obtained from the Ancore Corporation of Manhassett, Long Island, New York. The rats were approximately 30-50 days old when they arrived at the laboratory. They were housed in individual cages for 8 weeks before being tested. During this period all rats had continuous access to both food and water while on a 12-h light, 12-h dark illumination schedule. The rats remained on the same food-water and light-dark schedule during the 5-week experimental period.

\section{Apparatus}

Two Plexiglas restraining chambers $(6.5 \mathrm{~cm}$ wide, $6.5 \mathrm{~cm}$ high, and $24.5 \mathrm{~cm}$ long) were used. The back wall of each chamber was.hinged and served as the entrance into the chamber. A hole $(1.5 \mathrm{~cm}$ wide and $1.5 \mathrm{~cm}$ high) was cut into the back wall, enabling the rat's tail to extend out of the chamber. At this end of the chamber, the floor extended out another $25.5 \mathrm{~cm}$ beyond the hinged back wall. The rat's exposed tail was fastened to this floor extension with white medical tape. Ventilation holes were drilled into each of the three walls of the restraining chambers.

The restrained rats were placed in a sound-attenuating structure $(50.8 \mathrm{~cm}$ wide, $36.6 \mathrm{~cm}$ high, and $34.5 \mathrm{~cm}$ long). Two electrodes, covered with electrode paste, were placed $2 \mathrm{~cm}$ apart on preshocked (PS) rats' tails. For PS rats, shocks were delivered by a Lehigh Valley constant-current shocker, Model 113.04.

Testing chamber. One operant chamber $(15.4 \mathrm{~cm}$ wide, $27.0 \mathrm{~cm}$ high, and $23.8 \mathrm{~cm}$ long) was used for testing PS and control $(C)$ rats. Three of the chamber walls and the ceiling were clear Plexiglas; the other wall was aluminum. The chamber floor consisted of 16 stainless steel grids $.5 \mathrm{~cm}$ in diameter, spaced $.75 \mathrm{~cm}$ (center to center). A lever $(3.5 \mathrm{~cm}$ wide and $2.3 \mathrm{~cm}$ long) extended out from the aluminum wall. The lever was positioned $1.8 \mathrm{~cm}$ from the far corner of the chamber and $4.5 \mathrm{~cm}$ above the grid floor. The operant chamber was located inside the same sound-attenuating structure used with the restraining treatment apparatus. Constant illumination during testing was provided by a $1.5-\mathrm{W}$ light bulb fastened to the ceiling of the operant chamber. Scrambled shocks in the testing chamber were delivered by a Lehigh Valley solid state shocker/ scrambler, Model 113-33.

Recording apparatus. A running-time meter, accurate to $.1 \mathrm{sec}$, recorded cumulative escape latency, and a frequency counter recorded barpress escape responses. The sequencing of trials, intertrial intervals, and other aspects of the treatment conditions were programmed by Lehigh Valley electromechanical modules.

\section{Design}

The study consisted of a treatment phase and a testing phase. In the treatment phase, a 2 by 2 factorial design was used. The 32 male and 32 female rats were assigned to two treatment groups of 16 each. One group was designated the PS group; the other was designated the $C$ group. In the testing phase, each group of 16 was randomly divided into four groups of 4 according to assigned escape response contingencies: FR 2, FR 3, FR 4, and FR 5 barpresses. Animals in each FR group were randomly chosen to run either during the light or dark phase of the 12-h light, 12-h dark cycle.

\section{Procedure}

On Day $1,24 \mathrm{~h}$ prior to being placed into the treatment chamber, rats were deprived of food. Rats remained on a water diet throughout the treatment and testing procedures. (The water diet reduced the likelihood that the rats would defecate on the testing chamber's steel grids.)
On Day 2, a PS and a $\mathrm{C}$ rat were individually secured in their respective restraining treatment chambers. Both restrained PS and $\mathrm{C}$ rats were then placed in the sound-attenuating structure. The PS rat received a single session of inescapable shock, consisting of 80 presentations of $14 \mathrm{sec}$ of $1.0-\mathrm{mA}$ shock. Intervals between shocks were random, with a mean of $60 \mathrm{sec}$ and a range of $10-110 \mathrm{sec}$. The inescapable shock session lasted approximately $90 \mathrm{~min}$. The unshocked $\mathrm{C}$ rat remained in its restraining treatment chamber while the PS rat was being shocked.

On Day 3 , both PS and C rats were individually tested in the operant testing chamber using a barpress escape response. After approximately a $30-\mathrm{sec}$ adaptation period, $1.0-\mathrm{mA}$ of scrambled shock was delivered through the grids on the chamber floor. On each trial, shock was presented for a maximum of $60 \mathrm{sec}$ or until the rat escaped by pressing the lever the designated number of times.

Testing was conducted for 40 trials. Intertrial intervals were random with a mean of $60 \mathrm{sec}$ and a range of 10-110 sec. The total time required for a rat to escape shock was recorded for the 40-trial session, and each rat's mean escape latency period per trial was then calculated.

\section{RESULTS}

Mean escape latencies are shown for all groups in Figure 1.

Overall treatment effects showed PS rats were significantly slower to escape than the unshocked Cs $[F(1,48)=13.983, p<.01]$. Task difficulties differed reliably $[F(3,48)=4.067, p<.05]$. Newman-Keuls tests indicated that rats at the FR 4 level were significantly slower than rats at the FR 2 level. There were no other reliable differences among task difficulty levels.

There was an interaction between treatment and task difficulty $[F(3,48)=3.549, p<.05]$. Newman-Keuls tests showed that PS rats were slower to escape than $C$ rats at intermediate task-difficulty levels (FR 3 and FR 4) but not at extreme levels (FR 2 and FR 5).

An interaction between sex and task difficulty was also noted $[F(3,48)=4.129, p<.05]$. Newman-Keuls tests showed that males were affected by task-difficulty level, requiring longer escape latencies at FR 4 and FR 5 than at FR 2. For female rats there was no effect of task difficulty on escape latency. No other effects or interactions were significant.

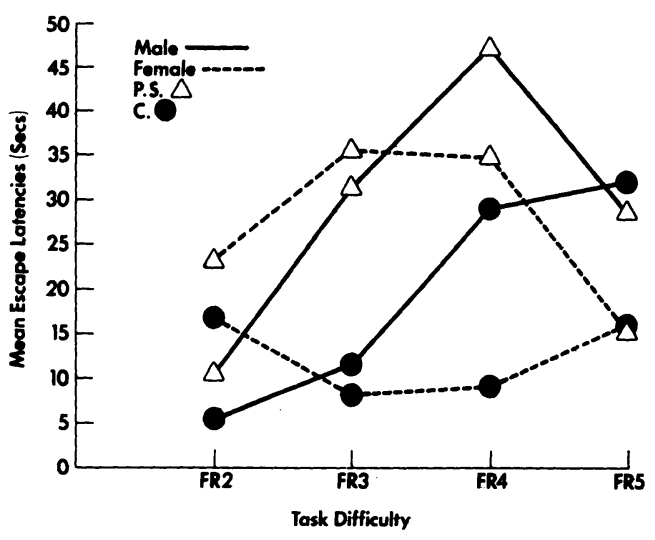

Figure 1. Mean escape latencies for all groups. 


\section{DISCUSSION}

Results are consistent with previous learned helplessness research at both FR 2 and FR 3 task-difficulty levels: PS rats at FR 2 did not differ reliably in escape latencies from corresponding $\mathrm{C}$ rats, whereas rats treated with inescapable shock and subsequently tested at the FR 3 requirement escaped at a significantly slower rate than nonshocked Cs. At the FR 4 level, results are also consistent with the learned helplessness model. FR 4 PS rats differed reliably from nonshocked Cs, escaping at a significantly slower rate. These results suggest that both FR 3 and FR 4 barpress escape responses are sensitive to pretreatment with inescapable shock.

The passive behavior of the PS rats at the FR 3 and FR 4 task-difficulty levels was characteristic of the learned helplessness behavior described in other research with "helpless" rats. In early trials, the PS rats jumped repeatedly during shock. These rats occasionally did terminate shock during their sporadic jumping before the 60 -sec shock interval expired. However, as the trials progressed, the jumping behavior declined, and the rats passively accepted the shock. This "helpless" behavior was manifested in various forms. Some rats huddled in a corner of the box, while others simply lay on the grid floor.

The FR 5 results are problematic. According to the learned helplessness model, the PS rats were expected to be helpless. However, they performed better at FR 5 than at FR 3 and FR 4. There is also the question of why rats at a higher task-difficulty level would outperform rats at lower task-difficulty levels. Neither the helplessness model nor simple logical expectations would predict better performance at higher task-difficulty levels. Examining barpress escape responses ranging from FR 4 to FR 7 may clarify the effects of inescapable shock at these higher levels of task difficulty. It is curious that task difficulty appears to be such an important variable in demonstrating the learned helplessness phenomenon. With respect to this theory, a closer consideration of what specifically determines response difficulty should be investigated. The present experiment used response frequency in examining effects of task difficulty on "helpless" behavior. Varying the weight of the bar itself is another possible way to demonstrate these effects. The model does not predict that "helpless" subjects are unable to perform any tasks (as shown in the ability of PS rats at the FR 2 level). It may be that the effects of helplessness interfere with a variety of tasks but only at specific levels of task difficulty. These issues should be considered in future studies.

This preliminary investigation of inescapable shock on sex differences suggests that this issue too is worthy of further attention. Although the overall effects of shock treatment did not differ between the sexes, it is interesting that the task difficulty affected performance of male rats but not females.
It would be appropriate to explore more fully the effects of inescapable shock on both male and female rats in future learned helplessness studies.

\section{REFERENCE NOTE}

1. Hughes, R. A., \& Bardo, M. T. Shuttlebox avoidance to different intensities of white noise by male and female rats. Paper presented at the annual meeting of the Psychonomic Society, St. Louis, 1976.

\section{REFERENCES}

Beatty, W., \& Beatty, W., \& Beatty, P. Hormonal determinants of sex differences in avoidance behavior and reactivity to electric shock in the rat. Journal of Comparative and Physiological Psychology, 1970, 73, 445-455.

David, H., Porter, J. W., Burton, J., \& Levine, S. Sex and strain differences in leverpress shock escape behavior. Physiological Psychology, 1976, 4, 351-356.

Denti, A., \& Exstein, A. Sex differences in the acquisition of two kinds of avoidance behavior in rats. Physiology \& Behavior, 1972, 8, 611-615.

LOONEY, T. A., \& COHEN, P. S. Retardation of jump-up escape responding in rats pre-treated with different frequencies of noncontingent electric shock. Journal of Comparative and Physiological Psychology, 1972, 78, 317-322.

Maier, S. F., Albin, R. W., \& Testa, T. J. Failure to learn to escape in rats previously exposed to inescapable shock depends on nature of escape response. Journal of Comparative and Physiological Psychology, 1973, 85, 581-592.

MAIER, S. F., \& TESTA, T. J. Failure to learn to escape by rats previously exposed to inescapable shock is partly produced by associative interference. Journal of Comparative and Physiological Psychology, 1975, 88, 554-564.

Rosellini, R. A., \& Seligman, M. E. P. Failure to escape shock following repeated exposure to inescapable shock. Bulletin of the Psychonomic Society, 1976, 7, 251-253.

Seligman, M. E. P. Helplessness: On depression, development and death. San Francisco: Freeman, 1975.

Seligman, M. E. P., \& Beagley, G. Learned helplessness in the rat. Journal of Comparative and Physiological Psychology, 1975, 88, 554-564.

Seligman, M. E. P., Rosellin, R. A., \& Kozak, M. J. Learned helplessness in the rat: Time course, immunization, and reversibility. Journal of Comparative and Physiological Psychology, 1975, 88, 542-547.

(Received for publication January $31,1979$. ) 